\title{
Penyelesaian Travelling Salesman Problem dengan Menggunakan Algoritma Artificial Bee Colony
}

\section{Hilda Chaerunnissa*, Respitawulan}

Program Studi Matematika, Fakultas Matematika dan Ilmu Pengetahuan Alam, Universitas Islam Bandung, Jl Tamansari No.1 Bandung 40116

*hildachaerunnissa@gmail.com, respitawulan@gmail.com

\begin{abstract}
Artificial bee colony algorithm is inspired by the honeybee's behavior in finding foods. In finding foods, the bees have 3 divisions that play an important role: the employed bees, the onlooker bees, and the scout bees. In this paper, the artificial bee colony algorithm implemented on the shipping problem conducted by courier. The courier should find the shortest route by passing through each and every specified location and coming back to the first location to deliver the packages in a short time. The efficient route to deliver the packages is solved by optimizing the travelling salesman problem. PT X has 18 drop-off locations. Using the artificial bee colony algorithm, the effective route was established with total range of $95.9 \mathrm{~km}$.
\end{abstract}

\section{Keywords: Travelling Salesman Problem, Artificial Bee Colony, PT X Shipping Process}

\begin{abstract}
Abstrak. Algoritma artificial bee colony ini terinspirasi dari perilaku lebah madu dalam mencari makanan. Dalam mencari makanan lebah tersebut memiliki 3 pembagian kerja, yaitu employed bees, onlooker bees, dan scout bees. Algoritma artificial bee colony dapat diimplementasikan dalam masalah pengiriman paket oleh kurir. Penyelesaian travelling salesman problem menggunakan algoritma artificial bee colony untuk mencari rute terpendek dengan melewati setiap lokasi yang ditentukan tanpa ada yang terlewat dengan kembali lagi ke lokasi awal agar seorang kurir dapat mengantarkan paket-paket tersebut dengan waktu yang singkat, sehingga masalah yang terjadi seorang kurir harus menemukan rute yang efisien di antara rute lainnya agar dapat menjalankan tugas dengan baik. Berdasarkan hasil program yang dilakukan pada 18 lokasi pengantaran oleh seorang kurir dengan menggunakan algoritma Artificial Bee Colony pada studi kasus pengiriman paket PT X memperoleh hasil rute dengan total jarak yaitu $95,9 \mathrm{~km}$.
\end{abstract}

Kata kunci: Travelling Salesman Problem, Artificial Bee Colony, Pengiriman Paket PT X 


\section{A. Pendahuluan}

Travelling Salesman Problem (TSP) merupakan masalah optimasi dengan tujuan untuk menentukan rute perjalanan yang dimulai dari lokasi awal kemudian mengunjungi beberapa lokasi hingga kembali lagi pada lokasi asal dengan setiap lokasi yang dikunjungi tepat hanya satu kali. Permasalahan TSP ini seringkali ditemukan dalam kehidupan sehari-hari seperti halnya dalam kasus pengiriman paket oleh salah satu perusahaan ekspedisi, dimana seorang kurir memiliki tugas untuk mengantarkan paket-paket tersebut ke setiap lokasi yang ditentukan tanpa ada yang terlewat dengan waktu yang singkat, sehingga masalah yang terjadi seorang kurir harus menemukan rute yang efisien di antara rute lainnya agar dapat menjalankan tugas dengan baik.

Salah satu algoritma yang dapat menyelesaikan proses pengiriman paket ini yaitu algoritma artificial bee colony yang terinspirasi dari perilaku lebah madu dalam mencari makanan. Algoritma artificial bee colony merupakan algoritma yang sederhana, fleksibel dan dapat secara efisiensi digunakan untuk multimodal dan multivariabel optimasi fungsi.

Adventia [1] telah menyelesaikan masalah pendistribusian barang menggunakan algoritma bee colony optimization. Penelitian selanjutnya dilakukan oleh Putra [2] untuk masalah travelling salesman problem dengan algoritma artificial bee colony pada pendistribusian hewan qurban PPHQ AMM. Artikel ini akan mendiskusikan tentang travelling salesman problem dengan menggunakan algoritma artificial bee colony berbantuan MATLAB, untuk kasus pada PT X.

\section{B. Metodologi}

\section{Travelling Salesman Problem}

Travelling Salesman Problem merupakan salah satu permasalahan optimasi untuk menentukan rute terpendek yang akan dilalui seorang salesman yang bertugas untuk mengirimkan suatu barang kepada seorang client. TSP juga merupakan suatu permasalahan sirkuit Hamilton [3]. Sirkuit Hamilton merupakan sirkuit yang melalui tiap simpul di dalam graf tepat satu kali, kecuali simpul asal (sekaligus simpul akhir) yang dilalui dua kali. TSP dapat diselesaikan dengan metode optimasi dengan adanya fungsi tujuan dan kendala.

Misalkan $x_{i j}$ merupakan variabel keputusan yang menunjukan seorang salesman melakukan perjalanan dari kota $i$ ke kota $j$ sebagai berikut:

$$
x_{i j}=\left\{\begin{array}{cc}
1 & \text { rute yang dilewati dari } i \text { ke } j \\
0 & \text { lainnya }
\end{array}\right.
$$

Misalkan $z$ merupakan fungsi tujuan dari model TSP dengan tujuan untuk meminimumkan rute seorang salesman dengan model matematika sebagai berikut:

$$
z=\sum_{i=1}^{n} \sum_{j=1}^{n} d_{i j} x_{i j}
$$

Dengan:

$\begin{array}{cll}z & : & \text { Fungsi tujuan } \\ d_{i j} & : & \text { Jarak kota } i \text { ke kota } j \\ i & : & \text { Kota awal } \\ j & : & \text { Kota tujuan }\end{array}$

Kendala dari permasalahan TSP ini yaitu setiap rute hanya dapat dikunjungi satu kali saja. Kendala yang pertama yaitu seorang salesman hanya dapat mengunjungi kota $i$ satu kali saja dengan model matematika seperti berikut :

$$
\sum_{i=1}^{n} x_{i j}=1, i, j=1,2, \ldots, n
$$

Kendala yang lainnya yaitu hanya dapat melewati kota $j$ satu kali saja dengan model matematika seperti berikut : 


$$
\sum_{j=1}^{n} x_{i j}=1, i, j=1,2, \ldots, n
$$

\section{Optimasi dengan Algoritma Artificial Bee Colony}

Optimasi adalah proses pencarian satu atau lebih penyelesaian untuk mendapatkan hasil terbaik di bawah keadaan yang diberikan. Tujuan akhir dari semua proses tersebut adalah meminimumkan usaha atau memaksimumkan manfaat yang diinginkan.

Algoritma optimasi terbagi menjadi dua jenis yaitu algoritma optimasi berbasis deterministic dan probabilistic. Salah satu algoritma yang termasuk kedalam algoritma optimasi dengan pendekatan berbasis probabilistic yaitu evolutionary computation. Algoritma ini memiliki gagasan dasar dari proses evolusi yang terjadi pada makhluk hidup dan dianggap hasil setiap evolusi merupakan sesuatu yang lebih baik atau optimal. Salah satu algoritma yang termasuk dalam kategori evolutionary computation yaitu swarm intelligence [4].

Swarm intelligence dapat diartikan sebagai kecerdasan kolektif atau kecerdasan kelompok, yaitu kecerdasan yang dihasilkan dari adanya tingkah laku suatu kelompok [5]. Khususnya algoritma Artificial Bee Colony terinspirasi dari perilaku lebah madu untuk mencari sumber makanan. Koloni dari lebah mampu menelusuri jarak sampai lebih dari $10 \mathrm{~km}$ dan juga mampu bergerak ke segala arah secara simultan untuk mencari lebih dari 1 sumber makanan [6]. Dalam mencari makanan lebah tersebut memiliki 3 pembagian kerja yang memiliki peranan penting pada setiap bagiannya, kelompok kerja tersebut yaitu :

1. Employed bees

Lebah yang termasuk pada kelompok lebah pekerja ini memiliki tugas untuk mencari sumber makanan pada wilayah tertentu yang pernah di kunjungi sebelumnya. Masingmasing lebah pekerja memiliki area yang berbeda dalam memperoleh sumber makanannya.

2. Onlooker bees

Lebah yang termasuk pada kelompok lebah pencari mempunyai tugas yaitu mengumpulkan informasi dari setiap lebah pekerja kemudian berkumpul dengan semua lebah pencari dan kemudian saling bertukar informasi lalu selanjutnya akan membuat keputusan berdasarkan informasi yang diberikan oleh lebah pekerja.

3. Scout bees

Lebah yang termasuk pada kelompok lebah pengintai bertugas untuk mencari sumber makanan pada wilayah tertentu yang sebelumnya tidak pernah dikunjungi.

Beberapa tahapan pada algoritma Artificial Bee Colony untuk permasalahan TSP diantaranya sebagai berikut [3]:

Langkah 1 - Inisialisasi

Membuat solusi random setiap Lebah Pekerja kemudian dihitung batas bawah dan batas atas untuk mencari nilai inisialisasi

$$
x_{i j}=x_{\min }^{j}+\operatorname{rand}[0,1]\left(x_{\max }^{j}-x_{\min }^{j}\right)
$$

$$
\text { Dengan: }
$$

$\begin{array}{cll}x_{i j} & : & \text { Lebah ke } i \text { pada dimensi ke-j } \\ x_{\max }^{j} & : & \text { Nilai batas atas pada dimensi ke-j } \\ x_{\min }^{j} & : & \text { Nilai batas bawah pada dimensi ke-j } \\ \operatorname{rand}[0,1] & : & \text { Bilangan acak dari } 0 \text { sampai } 1\end{array}$

Langkah 2 - Fase Employed Bee

Pilih neighbor dari Lebah Pekerja secara random dari $k$ dengan $k \neq i$, dimana $k, i \in$ $\{1,2, \ldots, S N\}$

Perbarui posisi dengan menggunakan persamaan berikut

$$
v_{i, j}=x_{i, j}+\operatorname{rand}[-1,1]\left(x_{i, j}-x_{k, j}\right)
$$

Jika nilai fitness / solusi yang baru hasilnya lebih tinggi dari sebelumnya maka solusi 
lama diperbarui dengan solusi baru, jika tidak maka trial ditambahkan dengan 1.

Langkah 3 - Fase Onlooker Bee

Hitung nilai fitness dari setiap solusi

$$
\operatorname{fitness}\left(x_{i}\right)=\left\{\begin{array}{cc}
\frac{1}{1+f\left(x_{i}\right)} & , f\left(x_{i}\right) \geq 0 \\
1+\operatorname{abs}\left(f\left(x_{i}\right)\right) & , f\left(x_{i}\right)<0
\end{array}\right.
$$

Hitung probabilitas setiap Lebah Pekerja dengan persamaan

$$
\operatorname{Prob}_{i}=\frac{\operatorname{fitness}\left(x_{i}\right)}{\sum_{k=1}^{S N} \operatorname{fitness}\left(x_{i}\right)}
$$

Perbarui posisi dengan menggunakan persamaan (2.2)

Jika nilai fitness / solusi yang baru hasilnya lebih tinggi dari sebelumnya maka solusi lama diperbarui dengan solusi baru, jika tidak maka trial ditambahkan dengan 1.

Langkah 4 - Fase Scout Bee

Hitung kumulatif dari nilai probabilitas dengan menggunakan persamaan

$$
q_{i}=\sum_{k=1}^{i} \operatorname{prob}_{k}
$$

Jika $q_{i}<\operatorname{rand}(0,1)$ maka hapus solusi lama dan digantikan dengan solusi baru dengan menggunakan persamaan $(2.1)$

Jika $q_{i}>\operatorname{rand}(0,1)$ maka memilih solusi sebelumnya.

Langkah 5 - Iterasi $=$ Iterasi +1

Langkah 6 - Stop jika sudah mencapai batas iterasi.

\section{Pembahasan dan Diskusi}

Data yang diperoleh merupakan sebuah data setiap lokasi yang harus dikunjungi oleh seorang kurir. Lokasi yang harus dikunjungi seorang kurir tersebut diantaranya Cihideung, Cikopak, Ciwangi, Cibaragalan, Cimaung, Cigelam, Sukamanah, Dangdeur, Bunder, Cibungur, Warung Kaler, Warung Mekar, Tirta Raya, Cilame, Cibening, Ciloajaya dan Ciloasari dengan titik awal berada pada PT X. Permasalahan yang dihadapi yaitu penentuan prioritas tujuan untuk menyusun rute dengan jarak yang paling minimum untuk mengoptimalkan waktu pengiriman paket.

Tahapan penyelesaian algoritma artificial bee colony dapat dilihat pada Gambar 1. Data jarak tempuh antar lokasi dapat dilihat pada Tabel 1 yang diperoleh dari aplikasi Google Maps. 


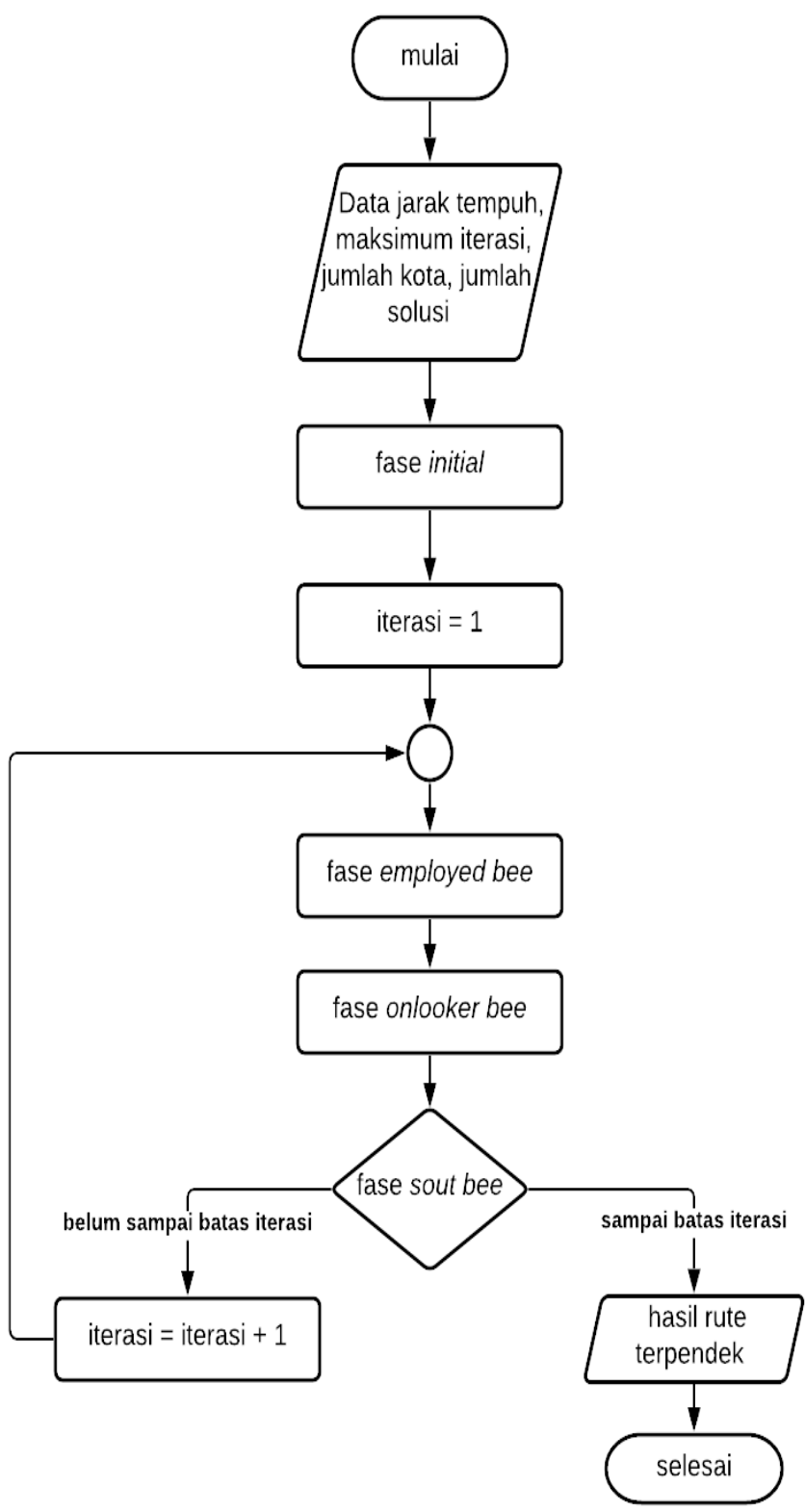

Gambar 1. Tahapan Algoritma Artificial Bee Colony 
Tabel 1. Data Jarak Tempuh Antar Lokasi PT X (km)

\begin{tabular}{|c|c|c|c|c|c|c|c|c|c|c|c|c|c|c|c|c|c|c|}
\hline & 1 & 2 & 3 & 4 & 5 & 6 & 7 & 8 & 9 & 10 & 11 & 12 & 13 & 14 & 15 & 16 & 17 & 18 \\
\hline 1 & 0,0 & 5,1 & 7,8 & 8,6 & 8,0 & 6,6 & 13,0 & 11,4 & 15,0 & 2,9 & 13,0 & 5,9 & 3,9 & 1,0 & 4,0 & 8,6 & 9,3 & 6,4 \\
\hline 2 & 5,1 & 0,0 & 11,2 & 11,4 & 11,4 & 10,5 & 16,5 & 14,9 & 18,6 & 6,9 & 18,7 & 18,8 & 15,1 & 14,6 & 14,4 & 12,5 & 13,0 & 11,0 \\
\hline 3 & 7,8 & 11,2 & 0,0 & 2,7 & 2,0 & 3,4 & 5,0 & 3,7 & 7,4 & 9,2 & 7,5 & 7,6 & 5,8 & 5,2 & 5,1 & 3,2 & 3,6 & 1,7 \\
\hline 4 & 8,6 & 11,4 & 2,7 & 0,0 & 0,7 & 1,8 & 7,9 & 6,3 & 10,1 & 10,1 & 8,6 & 4,9 & 4,4 & 3,8 & 3,7 & 1,8 & 2,2 & 2,5 \\
\hline 5 & 8,0 & 11,4 & 2,0 & 0,7 & 0,0 & 2,9 & 7,3 & 5,7 & 9,5 & 9,4 & 7,9 & 9,7 & 3,7 & 3,2 & 3,0 & 1,1 & 1,6 & 1,9 \\
\hline 6 & 6,6 & 10,5 & 3,4 & 1,8 & 2,9 & 0,0 & 8,7 & 7,1 & 10,8 & 8,8 & 10,8 & 11,0 & 6,6 & 6,0 & 5,9 & 4,0 & 4,4 & 3,2 \\
\hline 7 & 13,0 & 16,5 & 5,0 & 7,9 & 7,3 & 8,7 & 0,0 & 3,5 & 6,0 & 13,5 & 7,2 & 7,3 & 7,6 & 10,5 & 10,3 & 8,4 & 8,9 & 6,9 \\
\hline 8 & 11,4 & 14,9 & 3,7 & 6,3 & 5,7 & 7,1 & 3,5 & 0,0 & 4,3 & 12,9 & 4,4 & 3,9 & 4,6 & 5,7 & 6,5 & 6,8 & 7,3 & 5,3 \\
\hline 9 & 15,0 & 18,6 & 7,4 & 10,1 & 9,5 & 10,8 & 6,0 & 4,3 & 0,0 & 17,0 & 5,2 & 5,3 & 5,6 & 6,6 & 7,3 & 10,5 & 10,6 & 9,1 \\
\hline 10 & 2,9 & 6,9 & 9,2 & 10,1 & 9,4 & 8,8 & 13,5 & 12,9 & 17,0 & 0,0 & 16,4 & 16,5 & 12,8 & 12,2 & 12,1 & 10,6 & 10,6 & 7,5 \\
\hline 11 & 13,0 & 18,7 & 7,5 & 8,6 & 7,9 & 10,8 & 7,2 & 4,4 & 5,2 & 16,4 & 0,0 & 0,7 & 0,9 & 1,9 & 5,8 & 6,6 & 6,7 & 9,2 \\
\hline 12 & 5,9 & 18,8 & 7,6 & 4,9 & 9,7 & 11,0 & 7,3 & 3,9 & 5,3 & 16,5 & 0,7 & 0,0 & 0,6 & 1,6 & 2,4 & 10,8 & 7,0 & 9,3 \\
\hline 13 & 3,9 & 15,1 & 5,8 & 4,4 & 3,7 & 6,6 & 7,6 & 4,6 & 5,6 & 12,8 & 0,9 & 0,6 & 0,0 & 1,1 & 1,8 & 2,6 & 2,7 & 5,6 \\
\hline 14 & 1,0 & 14,6 & 5,2 & 3,8 & 3,2 & 6,0 & 10,5 & 5,7 & 6,6 & 12,2 & 1,9 & 1,6 & 1,1 & 0,0 & 1,2 & 2,0 & 2,1 & 5,0 \\
\hline 15 & 4,0 & 14,4 & 5,1 & 3,7 & 3,0 & 5,9 & 10,3 & 6,5 & 7,3 & 12,1 & 5,8 & 2,4 & 1,8 & 1,2 & 0,0 & 1,9 & 2,0 & 4,9 \\
\hline 16 & 8,6 & 12,5 & 3,2 & 1,8 & 1,1 & 4,0 & 8,4 & 6,8 & 10,5 & 10,6 & 6,6 & 10,8 & 2,6 & 2,0 & 1,9 & 0,0 & 0,5 & 3,0 \\
\hline 17 & 9,3 & 13,0 & 3,6 & 2,2 & 1,6 & 4,4 & 8,9 & 7,3 & 10,6 & 10,6 & 6,7 & 7,0 & 2,7 & 2,1 & 2,0 & 0,5 & 0,0 & 3,4 \\
\hline 18 & 6,4 & 11,0 & 1,7 & 2,5 & 1,9 & 3,2 & 6,9 & 5,3 & 9,1 & 7,5 & 9,2 & 9,3 & 5,6 & 5,0 & 4,9 & 3,0 & 3,4 & 0,0 \\
\hline
\end{tabular}

Sumber: Google Maps

Keterangan:

1. PT X

2. Cihideung

3. Cikopak

4. Ciwangi

5. Cibaragalan

6. Cimaung

7. Cigelam

8. Sukamanah

9. Dangdeur
10. Bunder

11. Cibungur

12. Warung Kaler

13. Warung Mekar

14. Tirta Raya

15. Cilame

16. Cibening

17. Ciloajaya

18. Ciloasari

Pengujian program dilakukan dengan cara merunning program atau memanggil ABCHIL pada command window, kemudian input data dan akan memperoleh hasilnya. Tampilan awal pada GUI ABCHIL dapat dilihat pada Gambar 2. 


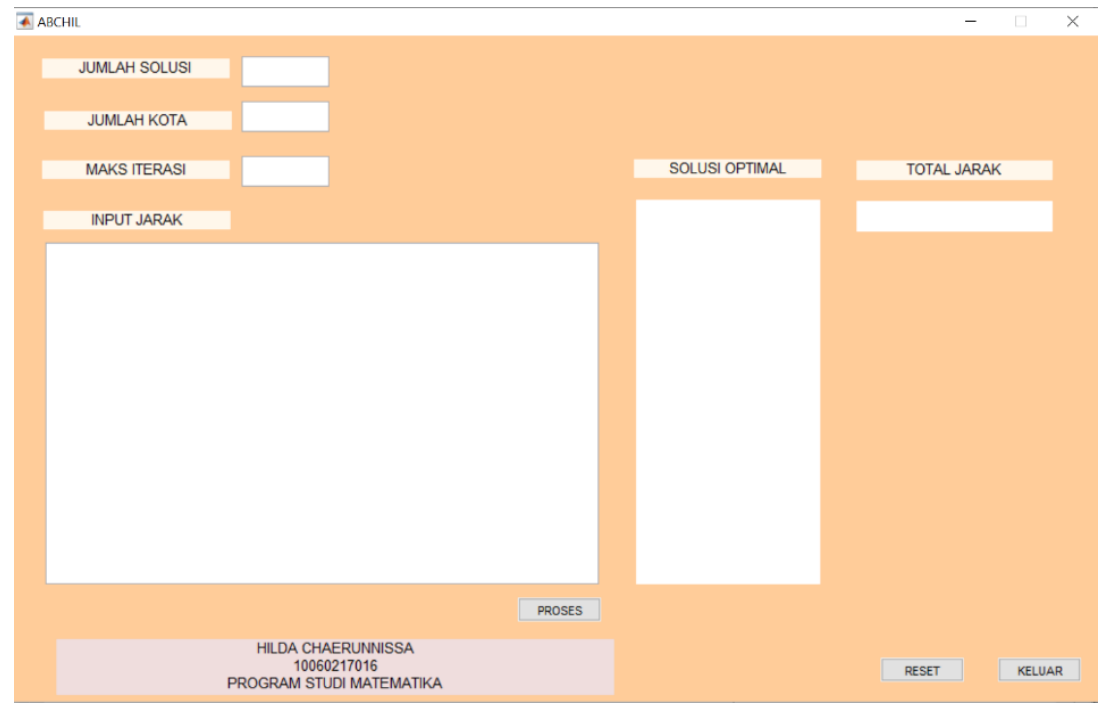

Gambar 2. Tampilan awal program

Pada Gambar 2. terdapat empat data yang harus diinputkan diantaranya jumlah solusi, jumlah kota, maksimum iterasi dan jarak tempuh. Input data pada penelitian ini adalah sebagai berikut :

- Jumlah kota $\quad: 18$

- Jumlah solusi $\quad: 4$

- Maksimum iterasi : 10

- Input jarak dapat diisi dengan matriks jarak berdasarkan Tabel 1.

Setelah input semua data maka tekan "PROSES" untuk memproses data yang sudah diinputkan, kemudian akan memperoleh hasil dari perhitungan Algoritma Artificial Bee Colony. Berikut adalah tampilan setelah menekan tombol "PROSES".

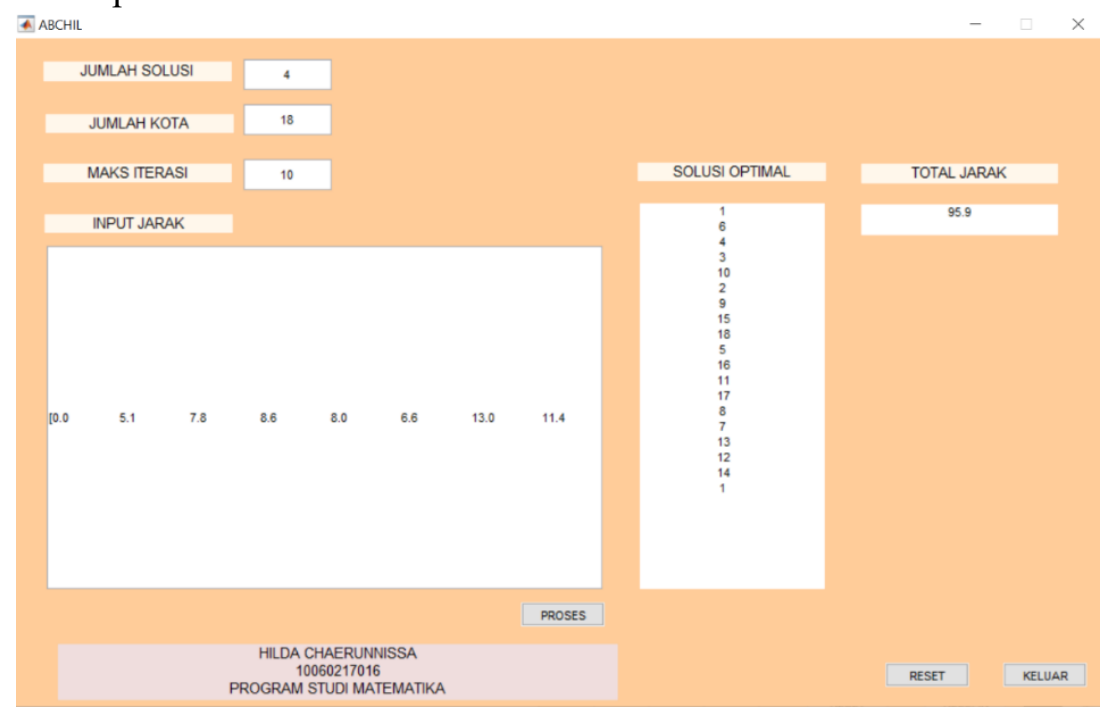

Gambar 3. Tampilan hasil program

Hasil penyelesaian menggunakan MATLAB dari masing-masing iterasi dapat dilihat pada Tabel 2. 
Tabel 2. Hasil Penyelesaian Menggunakan MATLAB

\begin{tabular}{|c|c|c|}
\hline Iterasi & Jarak $(\mathrm{km})$ & Galat (\%) \\
\hline 1 & 116,9 & 9,04851 \\
\hline 2 & 107,2 & 7,63052 \\
\hline 3 & 99,6 & 3,85819 \\
\hline 4 & 95,9 & 0 \\
\hline 5 & 95,9 & 0 \\
\hline 6 & 95,9 & 0 \\
\hline 7 & 95,9 & 0 \\
\hline 8 & 95,9 & 0 \\
\hline 9 & 95,9 & 0 \\
\hline 10 & 95,9 & \\
\hline
\end{tabular}

Output hasil program seperti pada Gambar 3, diperoleh beberapa hasil sebagai berikut: (a) Output solusi optimal adalah rute yang dilalui seorang kurir yang berawal dari PT X dan kembali lagi ke PT X. Rute Optimal yang dihasilkan sebagai 1-6-4-3-10-2-9-15-18-5-16-11-178-7-13-12-14-1. (b) Output total jarak adalah jarak total dari rute yang dihasilkan oleh solusi optimal yaitu $95,9 \mathrm{~km}$.

Solusi optimal diperoleh berdasarkan hasil pengujian dengan total jarak minimum pada iterasi ke-5 sehingga rute yang akan dikunjungi oleh seorang kurir ialah PT X - Cimaung Ciwangi - Cikopak - Bunder - Cihideung - Dangdeur - Cilame - Ciloasari - Cibaragalan Cibening - Cibungur - Ciloajaya - Sukamanah - Cigelam - Warung Mekar - Warung Kaler Tirtaraya - PT X dengan total jarak 95,9 km.

\section{Kesimpulan}

Hasil dari algoritma artificial bee colony yang dilakukan dengan menggunakan MATLAB pada studi kasus pengiriman paket PT X memperoleh rute hasil optimasi yaitu PT X - Cimaung Ciwangi - Cikopak - Bunder - Cihideung - Dangdeur - Cilame - Ciloasari - Cibaragalan Cibening - Cibungur - Ciloajaya - Sukamanah - Cigelam - Warung Mekar - Warung Kaler Tirtaraya - PT X dengan total jarak 95,9 km.

\section{Daftar Pustaka}

[1] Adventia, A., Novianingsih, K., \& Serviana, H. Penyelesaian Masalah Pendistribusian Barang Menggunakan Algoritma Bee Colony Optimization. Jurnal EurekaMatika, vol. 6, no. 2, pp 64-72, 2018.

[2] Putra, P. R. Penyelesaian Travelling Salesman Problem Dengan Algoritma Artificial Bee Colony. Skripsi. Program Studi Matematika, Fakultas Sains dan Teknologi, Universitas Islam Negeri Sunan Kalijaga. Yogyakarta.

[3] Cholissodin, I., \& Riyandani, E., Swarm Intelligence (Teori \& Case Study). Filkom UB, 2016.

[4] Nurdiana, D. Implementasi Algoritma Lebah Untuk Pencarian Jalur Terpendek Dengan Mempertimbangkan Heuristik. Mosharafa: Jurnal Pendidikan Matematika, vol. 4, no.2, pp. 66-74, 2015.

[5] Suyanto, Swarm Intelligence Komputasi Modern untuk Optimasi dan Big Data Mining. Bandung : Informatika, 2017.

[6] Sugioko, A. Perbandingan Algoritma Bee Colony dengan Algoritma Bee Colony Tabu List 
Hubungan Penyelesaian Travelling Salesman Problem dengan Menggunakan Algoritma ...| 45

dalam Penjadwalan Flow Shop. Jurnal Metris, vol. 14, no. 2, pp 113-120, 2013. 